Агаев Ф.T. ${ }^{1}$, Мамедова Г.А. ${ }^{2}$, Меликова Р.T. ${ }^{3}$

1,2,3 Институт Информационных Технологий НАНА, Баку, Азербайджан

1,2,3 depart10@iit.ab.az

\title{
ИКТ-ОБРАЗОВАНИЕ В АЗЕРБАЙДЖАНЕ: СОВРЕМЕННОЕ СОСТОЯНИЕ, ЗАРУБЕЖНЫЙ ОПЫТ, ПРОБЛЕМЫ И ПЕРСПЕКТИВЫ
}

\author{
Поступила: 30.05.2019 Исправлена: 17.06.2019 Принята: 05.07.2019
}

\begin{abstract}
В статье проведен сравнительный анализ высшего профессионального ИКТ-образования в развитых странах мира, показаны сходства и различия образовательных систем США, европейских стран, России и Азербайджана, проанализированы тенденции и особенности систем образования, представлен список востребованных на сегодня и в ближайшей перспективе ИТ-специиальностей. В статье также изложены проблемы, стоящчие перед высшими учебными заведениями, готовящими специиалистов ИТ-профиля. С учетом проведенного анализа ИТ-профильных учебных программ зарубежных вузов, рекомендачий международных организаций стандартизации, мониторинга рынка труда разработаны методические рекомендации для совершенствования ИКТ-образования в Азербайджане. Показана необходимость модернизации системы образования и приведения ее в соответствие с современными требованиями.
\end{abstract}

Ключевые слова: ИКТ-специальности, учебная программа, международные стандарты, структура учебной программы, сравнение учебных программ, новые ИТ-профили, модернизация системы образования.

\section{Введение}

Основной целью образования в высшем учебном заведении является подготовка квалифицированных, конкурентоспособных кадров, готовых к постоянному профессиональному росту, являющихся специалистами в своей профессии и способных выполнять соответствующие работы в смежных отраслях деятельности.

Современное информационное общество характеризуется своим интеллектуальным потенциалом, а именно способностью усваивать и использовать новые знания и технологии в практической жизни. Азербайджанскому обществу нужны квалифицированные кадры, владеющие новыми информационными технологиями и умеющие применять их в различных сферах деятельности $[1,2]$. Поэтому необходим процесс модернизации системы ИКТ-образования, учебные программы должны соответствовать мировым стандартам и профилю специализации.

Проблемы влияния глобализации на состояние системы образования достаточно широко освещались в работах таких известных авторов, как Дж.Левин, П.Джарвис, С.Маргинсон, М.Фезерстоун, Р.Нельсон [4-9] и др. В их трудах исследуется взаимодействие глобальной и национальной систем образования, обосновывается необходимость реформирования образования и приведения его в соответствие с современными требованиями.

Объектом исследования настоящей статьи являются ряд систем высшего образования стран Европы, США, Канады, Японии, Китая и др., а также отличительные особенности этих систем от ИКТ-образования в Азербайджане. Для этого необходимо решить следующие задачи:

- выбрать страны с различными системами высшего ИКТ-образования;

- выявить основные тенденции и особенности систем образования в этих странах;

- сделать выводы о преимуществах и недостатках этих систем. 
Целью исследования является разработка рекомендаций для совершенствования образовательных учебных программ ИКТ-специальностей, по которым проводится обучение в вузах Азербайджанской Республики. Актуальность проблем, изложенных в настоящей статье, определяется неотложностью перехода к модернизации национальной системы ИТ-профильного образования и приведения его в соответствие с требованиями создания информационного общества в Азербайджане.

\section{Требования международных организаций по стандартизации к образовательным программам ИКТ-специальностей}

В настоящее время образование учебных заведений строится на основе образовательных стандартов, которые устанавливают перечень изучаемых дисциплин и соответствующий объем учебной нагрузки. При этом учебная программа должна быть составлена таким образом, чтобы сформировать у обучающихся ключевые компетенции в конкретной предметной области и учитывать последовательность изучения дисциплин в соответствии с содержанием знаний и умений, освоенных ранее, чтобы выработать у студентов систематизированный запас знаний в области их профессиональных интересов $[3,10]$.

В последние годы международными организациями по стандартизации был разработан и принят ряд стандартов для преподавания информационных технологий в высших учебных заведениях, последними из которых являются:

- руководство по учебной программе на уровне бакалавра по направлению «Информационные технологии», 2008 [11];

- руководство по учебной программе на уровне бакалавра по направлению «Информационные системы», 2010 [12];

- руководство по учебной программе на уровне бакалавра по направлению «Компьютерные науки», 2013 [13];

- руководство по учебной программе на уровне бакалавра по направлению «Программная инженерия», [14];

- руководство по учебной программе на уровне бакалавра по направлению «Компьютерная инженерия». Финальный отчет, 2016 [15].

Каждый из вышеперечисленных документов является результатом труда сотрудников и представителей международных организаций по стандартизации АCM (Association for Computing Machinery) и IEEE (Institute of Electrical and Electronics Engineers), имеет модульную структуру организации, т.е. состоит из названий дисциплин, рекомендуемых для преподавания по данному профилю, тем и подтем. По каждой теме указывается рекомендуемое число обязательных лекционных и факультативных часов.

В последнее время в развитии ИТ произошли огромные изменения, связанные с появлением новых областей деятельности, - геоинформатика, биоинформатика, квантовая информатика, космическая информатика и т.д. Эти изменения нашли свое отражение в вышеперечисленных рекомендациях.

Настоящие документы представляют собой тщательный пересмотр предыдущих версий куррикулумов. В них были детально определены объемы знаний базового и профессионального уровней, переосмыслены и уточнены цели обучения. Так, в новой редакции CS2008 основное внимание было уделено таким важным направлениям информационных технологий, как обеспечение информационной безопасности (Information Assurance and Security), платформ-ориентированные программные разработки (Platformbased Development), позволяющим создавать программные продукты на разных платформах: сервис-ориентированной, предметно-ориентированной, бизнесориентированной, аппаратно-ориентированной, компонентно-ориентированной и др. В этом же документе особое внимание было акцентировано на изучении сетевых технологий 
(Networking and Communications), что является особенно актуальным в эпоху Smartтехнологий, облачных вычислений, интернета вещей (Internet of Things), 5G-сетей, мобильных сетей и т.д.

Новая версия куррикулума по программной инженерии (Software Engineering) SE2014 разработана на основе международного стандарта ISO 12207. B SE2014 подробно описаны дисциплины, объем знаний (темы и подтемы), которые необходимо освоить студенту для его будущей работы над программными проектами. В этом документе также приведены примеры учебных программ по разным направлениям специализации: методы программной инженерии (Software Engineering Methods), инструменты программной инженерии (Software Engineering Tools), безопасность программной инженерии и систем (Software and Systems Security).

По части разработки учебных программ компьютерной инженерии (Computer Engineering) в новом документе CE-2016 уточнен и дополнен перечень дисциплин. В частности, в новый куррикулум добавлены такие дисциплины, как:

- системное и инженерное проектирование (Systems and Project Engineering);

- подготовка к профессиональной практике (Preparation for Professional Practice);

- системное управление ресурсами (Systems Resource Management);

- защита информации (Information Security).

\section{Сравнение ИКТ-образования зарубежных стран}

Несмотря на различия образовательных систем (форма управления, содержание образовательных программ) в высших учебных заведениях различных странах мира, все они имеют общую структуру организации, состоящую из трех уровней: бакалавр, магистр, доктор философии. Кроме этого в настоящее время университетами зарубежных стран введены программы обучения с академическими степенями: бакалавра - Bachelor, Bachelor of Art, Bachelor of Science, Bachelor of Engineering и мастера - Master, Master of Art, Master of Science, Master of Engineering.

Образовательная программа большинства вузов Европы, Америки и др. зарубежных стран состоит из двух частей: major (основной, дисциплины по выбранной специальности) и minor (дополнительной, дисциплины по смежной специальности). На основе изучения дисциплин, входящих в minor, можно получить дополнительную квалификацию. В ведущих вузах зарубежных стран совокупность обязательных дисциплин (core level), обеспечивающих фундаментальную подготовку студентов, в зависимости от выбранной специальности составляет приблизительно 40-60\% от общего объема обучения $[16,17]$.

В некоторых европейских странах, таких, как Швеция, Дания, Германия, Финляндия и Италия, был выбран путь интенсивного реформирования системы образования [19, 20$]$. Университеты этих стран стараются дать студентам практическое, востребованное на рынке образование, которое будет способствовать их личному и общественному процветанию. А в университетах Великобритании и Шотландии вводят так называемые «сэндвич-курсы», дающие студентам возможность получить опыт практической работы уже во время учебы.

Переход к новому характеру взаимодействия науки, техники и технологий вызвал в этих странах необходимость формирования так называемого «опережающего» образования, т.е. такого изменения системы образования, при котором коренным образом меняются методы и цели обучения. Усилия педагогов этих вузов, прежде всего, направляются на развитие творческого и инновационного мышления, что положительно влияет на дальнейшее трудоустройство студентов и формирование персональной карьерной траектории в будущем [18].

Одними из первых среди экономически развитых стран мира, приступивших к изменению подходов к подготовке будущих инженеров и использованию новых 
информационных технологий в различных учебных дисциплинах, являются США. Еще в 1991 году министерством образования США была принята программа «Америка-2000: стратегия образования» [19]. В этой программе основным направлением реформы образования стало внедрение новых информационно-компьютерных технологий в обучение и управление образованием.

На сегодняшний день американская модель подготовки специалистов в области техники и технологий является весьма авторитетной и популярной. По этой модели для получения звания «бакалавр» после 12 лет обучения в средней школе необходимо еще четыре года обучаться в университете. Статус «профессиональный инженер» присваивается по истечении определенного срока успешной работы по выбранной специальности (не менее 7 лет) [20].

В США, Великобритании и ряде других стран степень магистра может быть академической, ориентированной на научно-исследовательскую деятельность, или профессиональной, направленной на повышение профессионального уровня по специальности.

В странах Запада и Америки на государственном уровне содержание и качество преподаваемых дисциплин не контролируются, однако гарантией качества образовательных программ являются система аккредитации образовательных программ и сертификация специалистов. В США таким органом является ABET (Accreditation Board for Engineering and Technology - Совет по аккредитации по инженерии и технологиям) [23]. Этой организацией разрабатываются стандарты, обеспечивающие оценку качества образовательных программ. На сегодняшний день большинство программ университетов Германии, Англии, Турции, Польши, Австрии, Мексики и других стран прошло аккредитацию АВЕТ.

В документах ABET сформулированы требования к образовательным программам инженерных специальностей. В частности, студенты, обучающиеся по направлению Electrical and Computer Engineering, должны иметь знания в областях естественных наук и математики, вычислительной техники и микроэлектроники, системного и прикладного программного обеспечения.

Во Франции и других странах Европы действует и другая организация по аккредитации - FEANI (Fédération Européenne d'Associations Nationales d'Ingénieurs Федерация европейских инженерных организаций в области техники и технологий)[24]. По данным этой организации, на сегодняшний день потребность рынка труда в специалистах, подготовленных к теоретическим исследованиям, составляет около $25 \%$, а потребность в специалистах, нацеленных на практическую деятельность, - около 75\%.

Членами FEANI являются Франция, Испания, Великобритания, Ирландия, Исландия, Греция, Венгрия, Австрия, Бельгия, Швейцария, Кипр и др. Основной целью образования в этих странах является подготовка студентов как для выполнения научноисследовательских, так и практических задач в области ИКТ.

В требованиях к образовательным программам по направлению Computer Science в университетах Америки, Канады, Австралии, Японии и ряда других стран около 30\% времени обучения в вузе должно отводиться на обучение профессиональным дисциплинам. Студенты должны научиться работать с различными системами и языками программирования, профессионально владеть одним языком программирования высокого уровня. Как минимум 16 семестров-часов отводится практической работе [17].

Кроме этого в учебный план должны быть включены гуманитарные и социальные предметы, способствующие пониманию широкого круга социальных и этических вопросов в области информатики.

В зарубежных университетах по каждому направлению специализации в области информационных технологий имеется банк дисциплин, которые непрерывно обновляются. 
Это позволяет учебным заведениям корректировать образовательные программы в соответствии с требованиями компаний и появлением новых профессиональных сфер деятельности. Студенты этих университетов имеют возможность выбрать из этого банка дисциплины для более детального изучения. Кроме этого помимо обязательных дисциплин студент, исходя из своих приоритетов, сам выбирает курсы дополнительного изучения из списка дисциплин, предлагаемых университетом. Наряду с этим студент сам выбирает, какие лекции он желает прослушать. Главное, чтобы он сумел сдать свой минимальный «норматив» (core courses), а уже потом - углубленное изучение других дисциплин (elective courses) [27].

Нашим национальным вузам нужно изучить этот опыт и при разработке образовательных программ создать для каждого направления ИКТ-специальности свой банк дисциплин.

Во многих вузах этих стран применяется междисциплинарный подход к обучению. К примеру, в Университете Беркли специализация в области ИКТ осуществляется по двум основным направлениям - «Электротехника и вычислительная техника» (ECE, Electrical and Computer Engineering), «Информатика и вычислительная техника» (CSE, Computer Science and Engineering), а также по ряду междисциплинарных направлений: «Машинная инженерия» (ME, Mechanical engineering), «Биостатистика» (BS, Biostatistics), «Управление технологиями» (MOT, Management of Technology), «Когнитивные науки» (CS, Cognitive Science), «Прикладные науки и технологии» (AS\&T, Applied Science and Technology) [25].

\section{Прогнозы Всемирного экономического форума, кадровые стратегии по специальностям ИТ-профилей на 2018-2022 гг.}

Эволюция информационных технологий, активное внедрение облачных вычислений, Smart-технологий, искусственного интеллекта, машинного обучения и др. приводит к появлению новых профессий и исчезновению старых.

В январе 2018 г. Всемирный экономический форум (ВЭФ) опубликовал отчет «Будущее рабочих мест» (The Future of Jobs), основанный на опросе 350 крупнейших компаний из более чем 20 стран мира, производящих около $70 \%$ мирового валового продукта (США, Англия, Россия, Сингапур, Индия, Германия и др.) [26]. В этом форуме рассматривалось будущее рабочих мест, рабочих задач, навыков и кадровых стратегий в период с 2018 по 2022 год, включая переподготовку работников и увеличение численности персонала в инновационных областях экономики.

В отчете форума представлены направления ИТ, положительно влияющие на рост бизнеса до 2022 года: увеличение применения больших данных (increasing availability of big data), развитие искусственного интеллекта (advances in artificial intelligence), развитие мобильного Интернета (advances in mobile Internet), развитие облачных технологий (advances in cloud technology), приложения и веб-торговля (app- and web-enabled markets), интернет вещей (internet of things), цифровая торговля (digital trade), криптография (encryption), дополненная и виртуальная реальность (augmented and virtual reality), стационарные роботы (stationary robots), 3D-печать (3D-printing), человекоподобные роботы (humanoid robots), воздушные и подводные роботы (aerial and underwater robots), негуманоидные наземные роботы (non-humanoid land robots), биотехнология (biotechnology).

В этом отчете также опубликован список востребованных в предстоящем периоде (2018-2022 гг.) ИТ-профессий:

- аналитики данных и ученые (Data Analysts and Scientists);

- специалисты по искусственному и машинному обучению (AI and Machine Learning Specialists);

- генеральный и операционный менеджеры (General and Operations Managers); 
- специалисты по большим данным (Big Data Specialists);

- специалисты по цифровой трансформации (Digital Transformation Specialists);

- специалисты по продажам и маркетингу (Sales and Marketing Professionals);

- специалисты по новым технологиям (New Technology Specialists);

- разработчики программного обеспечения и приложений (Software and Applications Developers);

- услуги информационных технологий (Information Technology Services);

- специалисты по автоматизации процессов (Process Automation Specialists);

- специалисты по организационному развитию (Organizational Development Specialists);

- инновационные профессионалы (Innovation Professionals);

- аналитики информационной безопасности (Information Security Analysts);

- специалисты по электронной коммерции и социальным медиа (Ecommerce and Social Media Specialists);

- пользовательский опыт и человек-машинный интерфейс (User Experience and Human-Machine Interaction);

- дизайнеры взаимодействий и специалисты по обучению и развитию (Designers Training and Development Specialists);

- специалисты и инженеры по робототехнике (Robotics Specialists and Engineers);

- информационное обеспечение и обслуживание клиентов (Client Information and Customer Service);

- дизайнеры услуг и решений (Service and Solutions Designers);

- специалисты по цифровому маркетингу и стратегии (Digital Marketing and Strategy Specialists).

\section{Современное состояние ИКТ-образования в Азербайджане: проблемы и перспективы}

На сегодняшний день на территории Азербайджанской Республики функционируют 42 высших учебных заведения, в половине которых студенты специализируются в области информационно-коммуникационных технологий. Среди них Азербайджанский технический университет, Бакинский государственный университет, Азербайджанский государственный университет нефти и промышленности, Нахчыванский государственный университет, Сумгайытский государственный университет и ряд других. Перечень основных ИКТ-специальностей этих вузов перечислен ниже (табл.1).

Сравнительный анализ опыта США, Японии, европейских стран и Азербайджана показал основные противоречия профессионального образования на современном этапе. Это возрастающие требования к высококвалифицированным кадрам, конкуренция на рынке труда, несогласованность содержания обучения в вузах с требованиями работодателей. Обращение к зарубежному опыту позволяет более критично подходить к проблемам подготовки национальных кадров, дает лучшее понимание путей совершенствования содержания и методов для повышения качества ИКТ-образования.

Для ответа на вопрос, насколько образовательная программа конкретного вуза соответствует современным требованиям и в каком направлении ее совершенствовать, полезно сопоставить ее с подготовкой в других странах. Детальное сравнение образовательных программ в университетах развитых стран и Азербайджана по содержанию и требованиям к результатам обучения позволит оценить как программу в целом, так и уровень преподавания отдельных ключевых дисциплин. 
Перечень основных ИКТ-специальностей вузов Азербайджана

\begin{tabular}{|c|l|}
\hline Код & \\
\hline & На уровне бакалавра: \\
050116 & Преподаватель информатики \\
050628 & Инженерия автоматизации процессов \\
050631 & Компьютерная инженерия \\
050632 & Инженерия информационных технологий и систем \\
050509 & Компьютерные науки \\
050627 & Инженерия электроники, телекоммуникации и радиотехники \\
050624 & Инженерия приборостроения \\
050629 & Инженерия механотроники и робототехники \\
050648 & Инженерия биомедицинской технологии \\
050655 & Информационные технологии \\
050656 & Системная инженерия \\
& На уровне магистра: \\
060628 & Инженерия автоматизации процессов \\
060631 & Компьютерная инженерия \\
060632 & Инженерия информационных технологий и систем \\
060509 & Компьютерные науки \\
060627 & Инженерия электроники, телекоммуникации и радиотехники \\
050624 & Инженерия приборостроения \\
050629 & Инженерия механотроники и робототехники \\
050648 & Инженерия биомедицинской технологии \\
050655 & Информационные технологии \\
050656 & Системная инженерия \\
010011 & Математическая кибернетика \\
010013 & Оптимизация и оптимальное управление \\
010019 & Экономико-математические методы оптимального управления \\
010040 & Прикладная математика \\
230401 & Информационные системы \\
\hline
\end{tabular}

Попытаемся теперь конкретизировать анализ, взяв для сравнения программы подготовки бакалавров по направлению «Компьютерная инженерия» Азербайджанского технического университета и рекомендации международных организаций АCM (The Association for Computing Machinery) и IEEE (The Institute of Electrical and Electronics Engineers) (табл.2).

При сравнении правой и левой частей таблицы 2 можно увидеть, что общее количество часов, предусмотренных учебной программой по специальности «Computer Engineering» в Азербайджанском техническом университете, совпадает с требованиями международных организаций по стандартизации ACM и IEEE и составляет 420 часов.

Детальное сравнение по дисциплинам «Схемотехника компьютеров», «Архитектура и организация компьютеров», «Компьютерные сети», «Безопасность аппаратного и программного обеспечения компьютеров», «Формальные языки и теория автоматов» показывает более или менее полный охват по тематике преподаваемых дисциплин. При сравнении дисциплины «Разработка программного обеспечения» следует отметить, что в Азербайджанском техническом университете уже второй год преподается предмет «Основы программной инженерии и проектирование». При изучении этого предмета студентам даются знания по проектированию и эксплуатации ПО, методам и моделям 
инженерии программного обеспечения, управлению проектами, профессиональным и этическим требованиям к специалистам ПО, затрагиваются проблемы, стоящие перед специалистами ПО.

Таблица 2

Сравнение учебной программы по направлению «Computer Engineering» («Компьютерная инженерия») Азербайджанского технического университета

и рекомендаций $\mathrm{ACM}$ и IEEE

\begin{tabular}{|c|c|}
\hline $\begin{array}{l}\text { Curriculum Guidelines for Undergraduate } \\
\text { Degree Programs in Computer Engineering, } \\
2016 \text { (Руководство по учебной программе на } \\
\text { уровне бакалавра по направлению } \\
\text { «Компьютерная инженерия», 2016) }\end{array}$ & $\begin{array}{c}\text { Учебная программа по } \\
\text { специальности «Компьютерная } \\
\text { инженерия» Азербайджанского } \\
\text { технического университета }\end{array}$ \\
\hline $\begin{array}{l}\text { Схемы и электроника [50 часов] } \\
\text { Компьютерная архитектура и организация } \\
\text { [60 часов] } \\
\text { Встроенные системы [40 часов] } \\
\text { Подготовка к профессиональной практике [20 } \\
\text { часов] } \\
\text { Вычислительные алгоритмы [30 часов] } \\
\text { Цифровой дизайн [50 часов] } \\
\text { Компьютерные сети [20 часов] } \\
\text { Информачионная безопасность [20 часов] } \\
\text { Обработка сигналов [30 часов] } \\
\text { Управление системными ресурсами [20 часов] } \\
\text { Системы и проектирование [35 часов] } \\
\text { Разработка программного обеспечения [45 } \\
\text { часов] }\end{array}$ & $\begin{array}{l}\text { Схемотехника компьютеров [60 } \\
\text { часов] } \\
\text { Микропроиессорные системь [45 } \\
\text { часов] } \\
\text { Кластеры и сети [75 часов] } \\
\text { Формальные языки и теория } \\
\text { автоматов [45 часов] } \\
\text { Безопасность аппаратного и } \\
\text { программного обеспечения } \\
\text { компьютеров [60 часов] } \\
\text { Компьютернье сети [75 часов] } \\
\text { Основы программной инженерии и } \\
\text { проектирование [60 часов] }\end{array}$ \\
\hline
\end{tabular}

Также в университете отдельно преподается дисциплина «Кластеры и сети» (которая отсутствует в левой части таблицы), при изучении которой студентам даются знания по архитектуре высокоэффективных кластеров, типам и моделям кластеров, программному обеспечению и их построению на основе компьютерной сети.

В правой части таблицы, т.е. в учебной программе Азербайджанского технического университета, отсутствуют дисциплины «Обработка сигналов», «Управление системными ресурсами», «Системы и проектирование», которые рекомендованы международными организациями по стандартизации. Эти дисциплины не преподаются в Азербайджанском техническом университете.

Кроме теоретических знаний и практики, в международных стандартах показано, что студент должен научиться работать в команде. В университетах развитых стран по всем направлениям ИКТ-образования студентам преподаются знания, готовящие их к профессиональной практике для работы в команде [11-15]. Это:

- командные подходы к междисциплинарному взаимодействию;

- эффективные коммуникационные стратегии;

- инженерные решения и социальные взаимодействия;

- профессиональные и этические обязанности;

- компромиссы в профессиональной практике;

- интеллектуальная собственность и правовые вопросы;

- вопросы бизнеса и управления и т.д. 
При этом выпускник ИКТ-профиля должен в работе руководствоваться стандартами, соответствующим инструментарием и техническими ограничениями, знать, как работает бизнес.

\section{Заключение}

Вхождение Азербайджана в мировое экономическое пространство предъявляет определенные требования к качеству подготовки ИКТ-специалистов. В условиях становления информационного общества образовательная программа вуза должна учитывать результаты мониторинга рынка труда и динамики макроэкономических изменений, исчезновение старых и появление новых видов экономической деятельности, связанных с применением ИКТ. Поэтому подготовка высокопрофессиональных специалистов в республике, способных использовать и внедрять передовые разработки информационных технологий на практике, становится стратегически важной задачей для общества.

На сегодняшний день в Азербайджане наблюдается дефицит высококвалифицированных специалистов, владеющих современными методами по разработке и применению информационных технологий в различных сферах деятельности.

Среди действующих государственных образовательных стандартов в сфере ИКТобразования присутствуют профили, дублирующие друг друга, чрезмерно узкие в современных условиях и устаревшие.

В вузах республики обучают знаниям и технологиям, которые в современном мире быстро устаревают. Это происходит не потому, что вузы плохие, а потому что сфера ИКТ быстро совершенствуется и появляются новые требования к специалистам. Студенты, завершившие обучение в университете, сегодня не готовы к серьезной работе, им приходится уже в процессе работы доучиваться, поэтому работодатели берут их на работу в качестве стажеров.

Таким образом, следует признать, что требуются модернизация и связанные с ней радикальные изменения в системе образования Азербайджана. Это является обязательным условием сохранения интеллектуального потенциала и достойного будущего для республики. Не следует при этом забывать, что модернизация образования означает переориентацию образовательного процесса на потребности общества в профессиональных и квалифицированных кадрах.

\section{Литература}

1. Государственная стратегия по развитию образования в Азербайджанской республике", утвержденная распоряжением Президента Азербайджанской Республики от 24 октября 2013 года.

2. Керимли Ф. Болонская система и развитие высшего образования Азербайджана // Научный диалог, 2013, № 2(14), с. 22-32.

3. Джуринский А.Н. Интернационализация высшего образования в современном мире, М.: Педагогика, 2004, 189 с.

4. Levin, J. S., Beach, J., \& Kisker, C.. Educational attainment skewed in California Community Colleges? // Community College Journal of Research and Practice, 2009, 33(3-4), c.256-269.

5. Levin, J. The revised institution: The community college mission at the end of the twentieth century. Community College Review, 2000, 28(2), c.1-25.

6. Jarvis P. Globalization, the Learning Society and Comparative Education // Comparative Education, 2000, Vol.36, No.3, P.346.

7. Marginson S. Dynamics of national and global competition in higher education // Higher Education, 2006, 52, pp. 1-39.

8. M. Featherstone (Ed.) Global culture: Nationalism, globalization and modernity Newbury Park, Sage Publications, pp. 295-310. 
9. Nelson R. The market economy and the scientific commons // Research Policy, 2004, 33, pp. 455-471.

10. Сухомлин В.А. ИТ-образование. Концепция, образовательные стандарты, процесс стандартизации, М., “Горячая линия - Телеком”, 2005, 176 с.

11. Information Technology 2008 (IT2008). Association for Computing Machinery and Computer Society of IEEE, http://www.acm.org//education/curricula/IT2008\%20 Curriculum.pdf.

12. Information Systems 2010 (IS2010). Association for Computing Machinery and Computer Society of IEEE, http://www.acm.org/education/curricula/IS\%202010\%20ACM\%20final.pdf.

13. CS2013 - Computer Science 2013: Curriculum Guidelines for Undergraduate Programs in Computer Science, http://www.acm.org/education/CS2013-final-report.pdf.

14. SE2014 - Software Engineering Curriculum Guideline, http://www.acm.org/education/se2014.pdf .

15. Guide to the Software Engineering Body of Knowledge. Version 3.0 (SWEBOK.v3). A Project of the IEEE Computer Society, http://www.computer.org/portal/ web/swebok.

16. Герова Н.В. Требования к результатам освоения основных образовательных программ бакалавриата и магистратуры для студентов в области изучения информатики и ИКТ // Педагогическое образование в России, 2014, № 8, сс. 94-98.

17. Образовательное законодательство и образовательные системы зарубежных стран. Под. ред. проф. А.Н. Козырина, М., Academia, 2007, 432 с.

18. Мамедова М.Г., Мамедзаде Ф.Р. Объектно-ориентированный подход к определению релевантности информационно-технологического образования на рынке ИТспециалистов. // Образование и наука, №5, 2014, с. 54-67.

19. "America 2000": A National Education Strategy, http://www.capenet.org

20. Ляшенко Е. Е. Формирование человеческого капитала в условиях реформирования высшего образования. Автореферат диссертации на соискание ученой степени кандидата экономических наук, Москва, 2012.

21. Гузаиров М.Б., Гаянова М.М., Козырева В.А. Сравнительный анализ образовательных программ в области информатики в университетах США и России // УГАТУ, 2010, № 4(39), cс. 166-174.

22. Обзоры системы высшего образования стран ОЭСР. Система высшего образования Германии, http://www.ecsocman.edu.ru/db/msg/157128.html.

23. ABET, Criteria for accrediting engineering program, October 20, 2017, https://www.abet.org

24. Handbook for National Monitoring Committees, 2009, http://www.feani.org

25. Berkley Academic Guide, http://guide.berkeley.edu/undergraduate/degree-programs

26. The Future of Jobs Report 2018 Centre for the New Economy and Society World Economic Forum // http://www3.weforum.org/docs/WEF_Future_of_Jobs_2018.pdf

27. Tomas U. Ganiron Jr. Evaluation of Engineering Programs towards Global Accreditation // World Scientific News, 2016 (59), pp. 97-108. 


\section{UOT 004.56}

Ăgayev F.T. ${ }^{1}$, Məmmədova G.A. ${ }^{2}$, Məlikova R.T. ${ }^{3}$

1,2,3 AMEA İnformasiya Texnologiyaları İnstitutu, Bak1, Azərbaycan

1,2,3 depart10@iit.ab.az

Azərbaycanda İKT təhsili: müasir vəziyyəti, xarici təcrübə, problemlər və perspektivlər

Məqalədə dünyanın inkişaf etmiş ölkələrinin ali təhsil müəsissələrində İKT ixtisasları üzrə təhsilin müqayisəli təhlili, ABŞ, Avropa ölkələri, Rusiya və Azərbaycanın təhsil sistemlərinin oxşarlığı və fərqləri göstərilir, təhsil sistemlərinin istiqamətləri və xüsusiyyətləri təhlil edilir, bu gün və yaxın gələcəkdə tələb olunan İKT ixtisaslarının siyahısı təqdim edilir. Bundan əlavə, məqalədə İKT profili mütəxəssis hazırlayan ali təhsil müəssisələrinin üzləşdiyi problemlər göstərilir. Xarici universitetlərin İKT profili tədris proqramların təhlili, standartlaşdırma üzrə beynəlxalq təşkilatların tövsiyələri, əmək bazarının monitorinqi nəzərə alınmaqla, Azərbaycanda İKT təhsili üçün metodik tövsiyələr hazırlanmışdır. Təhsil sisteminin müasirləşdirilməsi və müasir tələblərə uyğunlaşdırılması zərurəti göstərilir.

Açar sözlor: KT ixtisasları, tadris proqramı, beynalxalq standartlar, tadris proqramının strukturu, tədris proqramlarının müqayisasi, yeni İT profillari, təhsil sisteminin müəsirlaşdirilmasi.

\section{Firudin T. Aghayev', Gulara A. Mammadova ${ }^{2}$, Rena T. Melikova ${ }^{3}$}

1,2,3 Institute of Information Technology of ANAS, Baku, Azerbaijan

1,2,3 depart10@iit.ab.az

ICT education in Azerbaijan: current state, foreign experience, problems and prospects

The article comparatively analyzes the higher professional ICT education in the developed countries and highlights the similarities and differences of the educational systems of the United States, European countries, Russia and Azerbaijan. It analyzes the trends and features of the educational systems of the developed countries and provides a list of IT specialties in demand today and in near future. The article also outlines the problems facing higher education institutions that train IT profile specialists. Taking into account the analysis of the curriculum of IT profile of foreign universities, the recommendations of international organizations of standardization, monitoring of the labor market, methodical recommendations are developed to improve ICT education in Azerbaijan. The importance of modernization of the education system and its compliance with modern requirements is shown.

Keywords: ICT specialties, curriculum, international standards, curriculum structure, curriculum comparison, new IT profiles, modernization of the education system. 